[Agr. Biol. Chem., Vol. 33, No. 1, p. 43 49, 1969]

\title{
Pattern of Essential Amino Acid Requirement for Growing Rats Fed on a Low Amino Acid Diet
}

\author{
By Akira Yoshida* and Kiyoshi Ashida \\ Department of Agricultural Chemistry, Nagoya University, Nagoya \\ Received May 11, 1968
}

\begin{abstract}
Requirement pattern of essential amino acids for growing rats was investigated at low dietary level of nitrogen $(0.62 \%$ of nitrogen) for the basic knowledge of amino acid supplementation to low protein diets. The basal diet contained $30^{\circ}$ of essential amino acid mixture and $2 \%$ of non-essential amino acid mixture with appropriate amount of the other nutrients. The present pattern indicated relatively lower requirement for lysine and rather higher requirement for phenylalanine, valine and arginine as compared with those of several workers obtained for maximum growth of rats with diet containing sufficient amount of nitrogen. Application of dose response curves of each amino acid for the estimation of the order of the limiting amino acids was suggested.
\end{abstract}

Requirement of essential amino acids for growing rats was first estimated by Rose ${ }^{11}$ and recently it was slightly modified by Rama Rao et al., ${ }^{2 \prime}$ Rogers et al. ${ }^{3 \prime}$ and by Ranhotra et al. In In those experiments, diets contained enough nitrogen sources for the growth of rats. Based on these results the sequence of limiting amino acids and the extent of their deficiency in low protein diets are calculated. ${ }^{5 \sim 71}$ However, the sequence of amino acids which become limiting for the growth of rats was found sometimes to be quite different from that obtained by the calculation. ${ }^{6,10)}$ The reason is usually attributed to the difference of availa-

* Present Address: Department of Nutrition, School of Medicine, Tokushima University, Kuramotocho, Tokushima.

1) W. C. Rose, Science, 80, 298 (1937).

2) Rama Rao and B. C. Johnson, J. Nutrition, 73, 38 (1961)

3) Q. R. Rogers and A. E. Harper, ibid., 87, 267 (1965).

4) G. S. Ranhotra and B. C. Johnson, Proc. Soc. Exp. Biol. Med., 118, 1197 (1965).

5) L. J. Pecora and J. M. Hundley, J. Nutrition, 44, 101 (1951).

6) A.E. Harper, M. E. Winje, D. A. Benton and

C. A. Elvehjem, ibid., 56, 187 (1955).

7) H. R. Rosenberg and R. Culik, ibid., 63, 477 (1957). bility of each amino acid and the uncertainty of amino acid composition of proteins and/or uncertainty of amino acid requirement.

Supplement of amino acids to dietary proteins to improve their nutritional value is an important problem and amino acid imbalances induced by amino acid supplement is also significant. Practically, basic animal studies for these problems have been carried out with low protein diets. Therefore it is considered to be worthwhile to investigate the pattern of essential amino acid requirement for growing rats fed on a low amino acid diet. Present paper reports the amount of each essential amino acid required for the maximum growth of young rats fed on a diet containing about $5 \%$ of amino acid mixture $(0.62 \%$ of nitrogen).

\section{EXPERIMENTAL}

Male weanling rats of Donryu strain weighing from 40 to $50 \mathrm{~g}$ were used for the experiments five rats as a group. Most of the crystalline amino acids were kindly supplied from Ajinomoto Co. L-Isoleucine and DL-methionine were obtained from Tanabe Amino Acid Research Foundation. Only L-form of amino acids were used except DL-methionine, but in the ex- 
periment for the methionine requirement L-methionine was used. The mixture of essential amino acids used in the preliminary experiment was prepared according to the pattern of the requirement of essential amino acid determined by Rama Rao et al. ${ }^{2}$ ) Nonessential amino acid mixture contained L-glutamic acid, Laspartic acid, glycine and L-proline and the composition was arbitrarily selected as indicated in Table I. Both tyrosine and cystine were not included in the amino acid mixture. When the ratio of essential and nonessential amino acid was changed keeping the

\section{TABle 1. Composition of Amino Acid Mixture}

\begin{tabular}{lc}
\multicolumn{2}{c}{ Essential amino acids } \\
& $\%$ \\
L-Arg HCl & 4.65 \\
L-His HCl. $\mathrm{H}_{2} \mathrm{O}$ & 6.32 \\
L-Lys HCl & 20.8 \\
L-Try & 2.79 \\
L-Ileu & 10.2 \\
L-Val & 10.2 \\
L-Leu & 13.0 \\
L-Thr & 9.30 \\
DL-Met & 9.30 \\
L-Phe & 13.4 \\
$\quad$ Nonessential amino acids \\
& $\%$ \\
L-Glu & $\mathbf{5 4}$ \\
L-Asp & 20 \\
Gly & 14 \\
L-Pro & 12
\end{tabular}

TABLE II. Composition of BASAL DIET ${ }^{\prime \prime}$

$\begin{array}{ll} & \% \\ \text { Essential amino acids } & \\ \text { Nonessential amino acids } & 3.0 \\ \text { Vitamin mixture }^{3} \text { l } & 2.0 \\ \text { Choline. } \mathrm{HCl} & 0.85 \\ \text { Salt mixture } & 0.15 \\ \text { Sesame oil } & 4.0 \\ \text { Starch } & 2.0\end{array}$

Starch $^{41}$ to make $100 \%$

1) Diet contains $0.62 \%$ nitrogen.

2) The questionable essential amino acid was replaced by the isonitrogenous nonessential amino acid mixture.

3) A. E. Harper, J. Nutrition, 68, 405 (1959). 3000 I.U. of vitamin $A$ and 300 I.U. of vitamin D were also mixed with a kilogram of diet.

4) Alpha-type of potato starch obtained from Terahiko Starch Mfg. Co. dietary amino acid level at 5\%, gain in body weight was almost constant when the essential amino acid mixture occupied the 55 to $100 \%$ of total amino acids and it slightly decreased when the percentage was lowered to $40 \%$. Based on the result of this preliminary experiment, a diet containing $3 \%$ of essential amino acids and $2 \%$ of nonessential amino acids was used as a basal diet in the following experiments. Composition of the basal diet is shown in Table II. The level of one of the essential amino acid was changed variously keeping the dietary level of nitrogen constant by the adjustment with the nonessential amino acid mixture. Maximum level of each essential amino acid tested was a requirement value determined by Rama Rao et al. ${ }^{2}$ Both diet and water were supplied ad libitum. Experimental period was 3 weeks and body weight was measured twice a week.

\section{RESULT}

The relationship between the dietary level of one essential amino acid in question and the gain for 3 weeks is shown in Fig. 1 to 5 . The figures were drawn by free hand, but the levels of each essential amino acid required for maximum weight gain and for the maintenance of body weight were calculated by Lagrange's interpolation formula ${ }^{12)}$ using a computor of Tosback 3400 . The points obtained by the calculation are indicated as closed circles and the points obtained by the experiments are indicated as open circles in Fig. 1 to 5 . In the case of arginine requirement, gain in body weight increased in proportion to the dietary level of arginine until the body gain became plateau. Dietary level of arginine required for reaching the body gain plateau was adopted as an arginine requirement and it directly obtained from the figure. In general, the growth of rats increased fairly proportionally with each increase of the dietary level of an essential amino acid in question within a certain range and the rate of increase gradually diminished near the peak. The growth response curves were not straight but sigmoidal.

12) T. Uno, "Numerical Analysis for Computor", p. 124, Asakura Pub. Inc. Tokyo (1963). 


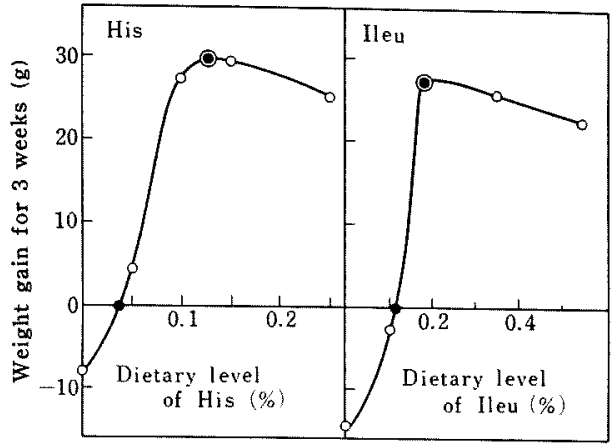

FIG. 1.

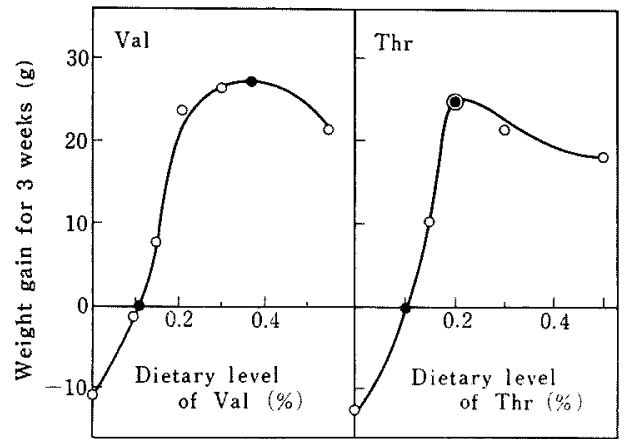

FIG. 3.

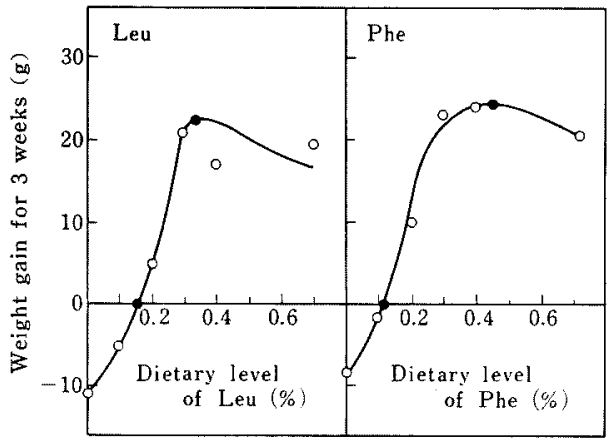

FIG. 2.

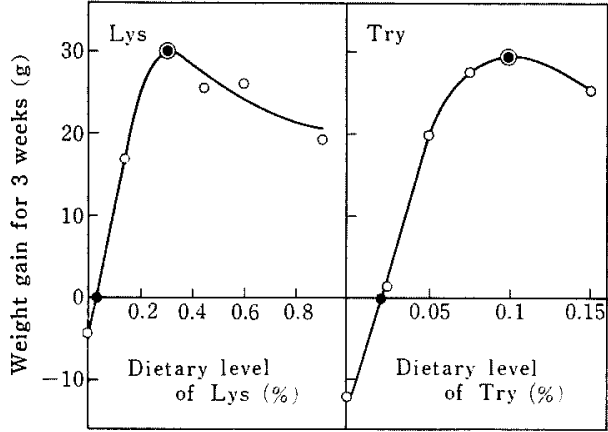

FIG. 4.

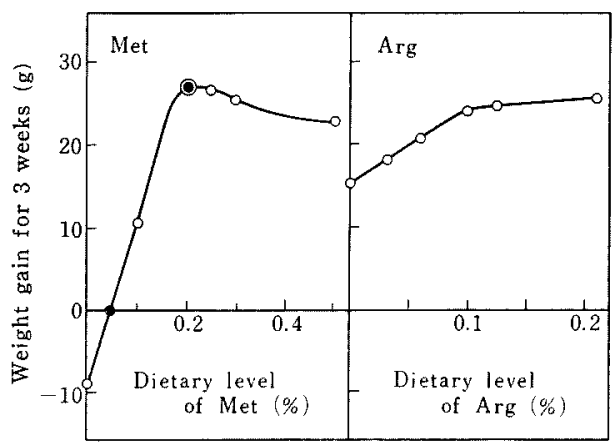

FIG. 5.

FIG. 1 5. Effect of Dietary Level of an Essential Amino Acid on the Growth Response of Rats in a Condition of Low Dietary Level of Nitrogen ( $0.62 \%$ of $\mathrm{N}$ ).

The level of an essential amino acid in the basal diet was variously changed keeping the dietary level of nitrogen at $0.62 \%$ by replacing of isonitrogenous nonessential amino acid mixture.

$O$ indicates the point obtained from the experimental data and $\bigcirc$ indicates the point of maximum response or maintenance requirement calculated according to the Lagrange's interpolation formula. 
The sigmoidal nature of the curve was pretty clear in the cases of histidine, valine and of tryptophan. Above the level of maximum growth, further addition of an essential amino acid rather decreased the growth of rats except the case of arginine.

\section{Histidine}

Without histidine in the diet, animals lost their body weight $8.0 \mathrm{~g}$ for 3 weeks. Maximum growth was obtained at $0.13 \%$ of dietary level of histidine. For the maintenance of body weight in this dietary condition, histidine seemed to be required about $0.04 \%$ of the diet (Fig. 1).

\section{Isoleucine}

Weight loss of rats on the isoleucine free diet was the greatest among those of animals on diets devoid of one of the essential amino acids and the weight loss was $14.7 \mathrm{~g}$ for 3 weeks. However the increase of weight gain with each increase of dietary isoleucine was quite sharp and the level of isoleucine for maximum growth was estimated to be $0.18 \%$. Maintenance requirement was estimated to be about $0.11 \%$ (Fig. 1).

\section{Leucine}

Loss of body weight of rats fed on the leucine free diet for 3 weeks was $10.8 \mathrm{~g}$. The dietary level of leucine for maximum growth was estimated to be about $0.33 \%$. Maintenance requirement was about $0.16 \%$ (Fig. 2).

\section{Phenylalanine}

Without phenylalanine in the diet, animals lost their body weight about $8.4 \mathrm{~g}$. Maximum growth was obtained at $0.45 \%$ of dietary level of phenylalanine. Maintenance requirement was estimated to be about $0.12 \%$ (Fig. 2).

\section{Valine}

On the valine free diet, animals lost their body weight about $11 \mathrm{~g}$ for 3 weeks. Maximum growth was obtained at $0.37 \%$ of dietary level of valine. Maintenance requirement was estimated to be $0.11 \%$ (Fig. 3).

\section{Threonine}

On the threonine free diet, animals lost their body weight about $12 \mathrm{~g}$ for 3 weeks. Maximum growth was obtained at $0.20 \%$ of dietary level of threonine. Maintenance requirement was estimated to be $0.10 \%$ (Fig. 3).

\section{Lysine}

When animals were fed on a diet devoid of one essential amino acid, animals lost their body weight about $10 \mathrm{~g}$ in most cases, while the body weight loss of animals on the lysine free diet was only $4.2 \mathrm{~g}$ for 3 weeks. Maintenance requirement was also relatively small, it was $0.03 \%$. Maximum growth was obtained at $0.30 \%$ of dietary level of lysine. Over the level of $0.30 \%$, growth was clearly retarded (Fig. 4).

\section{Tryptophan}

Loss of body weight of animals on the tryptophan free diet for 3 weeks was $12 \mathrm{~g}$. Maximum growth was obtained around $0.10 \%$ of dietary level of tryptophan. Maintenance requirement was estimated to be about $0.02 \%$ (Fig. 4).

\section{Methionine}

On the methionine free diet, animals lost their body weight about $9 \mathrm{~g}$. The increase of growth with each increase of dietary level of methionine was pretty steep and maximum growth was obtained at about $0.20 \%$ of dietary level of methionine. Over this level, slight and gradual decrease of growth was observed. Maintenance requirement was estimated to be about $0.05 \%$ (Fig. 5).

\section{Arginine}

Without arginine in the diet, animals gained about $15 \mathrm{~g}$ for 3 weeks and the growth gradually increased with each increase of dietary level of arginine until $0.11 \%$ and almost constant 
growth was obtained over this dietary level of arginine (Fig. 5).

\section{DISCUSSION}

One of the important factors that affect the value of the amino acid requirement is a technical problem how to determine the requirement from the dose-response curve. This problem was discussed by Hegsted ${ }^{131}$ in detail, he presented a hypothetical dose-response curve and suggested that the intersection of the line representing the linear response with the point of maximum response might be taken as the best estimate of the minimum requirement in spite of his recognition that it was not easy to determine whether the response was indeed proportional to the dose upon an arithmetic or logarithmic scale. It is obvious from both his hypothetical dose-response curves and the acid which might give the maximum response was calculated using Lagrange's interporation formula as described previously, and tentatively adopted as the requirement. One of the disadvantages of this method is a possibility to lead to a big error if the response gives a plateaulike curve over a wide range. Nevertheless, the authors tentatively adopted to investigate the characteristic feature of each essential amino acid.

The ratio of each amino acid requirement to the requirement of threonine was calculated and compared with those obtained from the amino acid requirement determined by Rose ${ }^{11}$ and Rama Rao et al. ${ }^{21}$ (Table III) The absolute requirement of each essential amino acid in the present experiments is lower than those of the other two reports because of the low dietary level of nitrogen. However, the pattern of essential amino acid requirement was pretty

TABle III. Comparison of the Pattern of the Essential Amino ACId Requirement

\begin{tabular}{lcccccc} 
& \multicolumn{2}{c}{} & \multicolumn{2}{c}{ Rama Rao et al. ${ }^{21}$} \\
His & 0.13 & 0.65 & 0.4 & 0.80 & 0.25 & Ratio \\
Heu & 0.18 & 0.90 & 0.5 & 1.0 & 0.55 & 1.1 \\
Leu & 0.33 & 1.7 & 0.8 & 1.6 & 0.70 & 1.4 \\
Phe & 0.45 & 2.3 & 0.9 & 1.8 & 0.72 & 1.4 \\
Val & 0.37 & 1.9 & 0.7 & 1.2 & 0.55 & 1.1 \\
Thr & 0.20 & 1.0 & 0.5 & 1.0 & 0.50 & 1.0 \\
Lys & 0.30 & 1.5 & 1.0 & 2.0 & 0.90 & 1.8 \\
Try & 0.10 & 0.50 & 0.2 & 0.40 & 0.15 & 0.30 \\
Met & 0.20 & 1.0 & 0.6 & 1.2 & 0.50 & 1.0 \\
Arg & 0.11 & 0.55 & 0.2 & 0.40 & 0.21 & 0.42
\end{tabular}

1) cf: Reference 1 in the text.

2) cf: Reference 2 in the text.

present data that the response is not linear near the maximum response, therefore the above method will invariably lead to a low estimate of the requirement. In the present paper the dietary level of one essential amino

13) D. M. Hegsted, "Mammalican Protein Metabolism" "Vol. II, ed. by H. N. Munro and J. B. Allison, Academic Press, New York and London, 1964, p. 137. similar among these three patterns except for relative requirement of lysine, phenylalanine, valine and arginine. The ratio of lysine requirement to that of threonine proposed by Rose $^{11}$ and by Rama Rao et al. ${ }^{2 \prime}$ were 2.0 and 1.8 respectively, while the present result showed 1.5. This lower value for lysine may due to its relatively low value of maintenance requirement for lysine compared with those of other 
essential amino acids. However, it may be questionable whether this difference of lysine requirement is due only to the difference of dietary level of nitrogen because Miyazaki also reported rather lower lysine requirement of rats with diets containing enough dietary level of nitrogen. ${ }^{81}$

Relative requirement of arginine was also rather higher than those of Rama Rao et al. and Rose. This tendency is accord with the modification of the essential amino acid requirement pattern of Rama Rao et al. by Ranhotra and Johnson. "' Their relative arginine requirement for threonine was 0.83 . Relative requirements of valine and phenylalanine are also high in the present result, but the relative requirements of most of other amino acids are in the range between those by Rose and Rama Rao et al.

From the figure of the relationships between growth and the dietary level of an essential amino acid, maintenance requirement of each essential amino acid was estimated and the ratio of them was calculated (Table IV). There are differences between the patterns of essential amino acid requirement for maintenance and growth. The ratio expressed threonine require-

Table IV. Maintenance Requirement of Essential Amino Acids at the Present DIETARY LEVEL OF NITROGEN

$\begin{array}{lcc} & \begin{array}{c}\text { Maintenance } \\ \text { requirement }\end{array} & \text { Ratio } \\ \text { His } & \% & \\ \text { Ileu } & 0.04 & 0.4 \\ \text { Leu } & 0.11 & 1.1 \\ \text { Phe } & 0.16 & 1.6 \\ \text { Val } & 0.12 & 1.2 \\ \text { Thr } & 0.11 & 1.1 \\ \text { Lys } & 0.10 & 1.0 \\ \text { Try } & 0.03 & 0.3 \\ \text { Met } & 0.02 & 0.2 \\ \text { Arg } & 0.05 & 0.5\end{array}$

8) M. Miyazaki, "Report of the Research Committee of Essential Amino Acids (Japan)", No. 23, 33 (1965). ment as a unity indicates lysine requirement for maintenance was especially little as compared with that for growth. Similar tendency was also observed for phenylalanine, tryptophan and methionine. But the relative maintenance requirement for other essential amino acid was pretty proportional to those of the relative requirement for growth. Maintenance requirement of amino acids for adult rats was reported by Frazier et al. ${ }^{91}$ Their result also indicated the comparatively low lysine requirement for the maintenance and the present result may partly relate to this fact because of the low dietary nitrogen in which case the maintenance requirement occupies the rather high portion of the total requirement (for maintenance and growth). The order of the limiting amino acids or the extent of the deficiency of an amino acid has been calculated on the basis of the requirement for the maximum growth of each amino acid comparing with that of the dietary content of amino acid assuming the nutritional effect of the deficit of any one of the essential amino acid is same if the deficit of an amino acid expressed by percentage of the requirement for maximum growth is same.

However the present result of the doseresponse curve of each essential amino acid indicates that the effects on growth of different essential amino acids are different even if the dietary level of those essential amino acid expressed as percentages of the requirement are same.

When an essential amino acid is included in a diet to suffice $50 \%$ of the requirement ( $50 \%$ deficiency), the expected body gain could be calculated from the Figs. $1 \sim 5$ by the Lagrange's interpolation formula as described previously. The estimated body gains obtained in this way are listed in Table $\mathrm{V}$ for each essential amino acid, and the gains are expressed as percentage of the maximum response of each set of experiments (cf. Figs. 1 5).

9) L. E. Frazier, R. L. Woalridge, C. H. Steffe, E. P. Benditt, Fed. Proc., 8, 835 (1949). 
TABLE V. WEIGHT GaIN OF Rats ON A DIET IN WHICH THE LEVEL OF ONE OF THE ESSENTIAL AMINo ACIDS JUST SUFFICE THE $50 \%$ OF THE REQUTREMENT IN THE PRESENT Dietary LEVEL OF NITROGEN ${ }^{\text {H }}$

$\begin{array}{lc}\text { Amino acid } & \begin{array}{c}\text { Gain at } 50 \% \text { of requirement } \\ (\% \text { of the max. gain })\end{array} \\ \text { Isoleucine } & -17.5 \\ \text { Threonine } & -1.6 \\ \text { Leucine } & 1.5 \\ \text { Methionine } & 37.9 \\ \text { Histidine } & 41.3 \\ \text { Lysine } & 56.5 \\ \text { Valine } & 60.9 \\ \text { Phenylalanine } & 63.1 \\ \text { Tryptophan } & 71.4 \\ \text { Arginine } & 82.2\end{array}$

1) Calculations were carried out according to the Lagrange's interpolation formula using a computor of TOSBACK-3400. Values are expressed as percentage of maximum gain in each set of experiments (cf. Figs. $1 \sim 5$ ).

When one of threonine, isoleucine and leucine is $50 \%$ deficient in the present experimental condition, animals are expected to grow about -17.5 to $1.5 \%$ of the maximum gain of this dietary level of nitrogen, while the similar deficiency of one of lysine, tryptophan, phenylalanine and valine would allow to grow about $60 \%$ or more of the maximum gain at the present dietary level of nitrogen. Thus, the effects on body gain of the partial deficiency of each amino acid are quite different and it might be reasonable to be emphasized this difference is taken into account for the estimation of the order of the limiting amino acids or the extent of partial deficiency of each amino acid although these differences might be less if the requirement is determined from the intersection of the line representing the linear response with the point of maximum response. $^{131}$

The effect of amino acid supplement is not necessarily as such that is expected from the conventional calculation. ${ }^{6,10,111}$ There are several possible reasons, ${ }^{6}$ and the present suggestion may also partly contribute for the understanding of the phenomena.

Acknowledgement. The authors are greatly indebted to Prof. T. Sato of Tokushima University for mathematical procedures.

10) L.J. Pecora and J. M. Hundley, J. Nutrition, 44, 101 (1951).

11) A. Yoshida and K. Ashida, Japan. J. Food and Nutrition, 20, 432 (1968). 